\title{
Fruit and vegetable intake and risk of CHD: results from prospective cohort studies of Chinese adults in Shanghai
}

\author{
Danxia Yu ${ }^{1}$, Xianglan Zhang ${ }^{1 *}$, Yu-Tang $\mathrm{GaO}^{2}$, Honglan $\mathrm{Li}^{2}$, Gong Yang ${ }^{1}$, Jie Huang ${ }^{1}$, Wei Zheng ${ }^{1}$, \\ Yong-Bing Xiang ${ }^{2}$ and Xiao-Ou Shu ${ }^{1}$ \\ ${ }^{1}$ Division of Epidemiology, Department of Medicine, Vanderbilt Epidemiology Center, Vanderbilt University Medical Center, \\ Vanderbilt University School of Medicine, 2525 West End Avenue, Suite 600, IMPH, Nashville, TN 37203-1738, USA \\ ${ }^{2}$ Department of Epidemiology, Shanghai Cancer Institute, 2200 Xie Tu Road, Shanghai, People's Republic of China
}

(Submitted 28 January 2013 - Final revision received 12 June 2013 - Accepted 18 June 2013 - First published online 19 July 2013 )

\section{Abstract}

The protective effects of fruits and vegetables against CHD have been suggested by many epidemiological studies among Western populations. However, prospective data are lacking for Asian populations. In the present study, we examined the associations of fruit and vegetable intake with CHD incidence among 67211 women (aged 40-70 years) and 55474 men (aged 40-74 years) living in Shanghai, China. Food intake was assessed using validated FFQ through in-person interviews. Coronary events (non-fatal myocardial infarction or fatal CHD) were identified by biennial home visits and further confirmed by medical record review. During a mean follow-up period of 9.8 and 5.4 years, 148 events in women and 217 events in men were documented and verified. After adjustment for potential confounders, women in the highest quartile of total fruit and vegetable intake (median $814 \mathrm{~g} / \mathrm{d}$ ) had a hazard ratio (HR) of 0.62 (95\% CI 0.38, 1.02) for CHD ( $P$ for trend=0.04) compared with those in the lowest quartile (median $274 \mathrm{~g} / \mathrm{d}$ ). This association was primarily driven by fruits (HR for the highest $v$. the lowest intake in women: $0.62,95 \% \mathrm{CI} 0.37,1.03$ ). The strength of the association was attenuated after further controlling for history of diabetes or hypertension. For men, no significant association was found for fruit and vegetable intake when analysed either in combination or individually. The present findings suggest that a high consumption of fruits may reduce CHD risk in Chinese women.

\section{Key words: Fruits: Vegetables: CHD: Prospective studies}

Fruits and vegetables have been widely considered as the essential components of a healthy diet, and their protective effects against CHD have been evaluated in many epidemiological studies ${ }^{(1)}$. In a recent meta-analysis of prospective studies, daily consumption of more than five portions (about $400 \mathrm{~g}$ ) of fruits and vegetables has been reported to be related to a $17 \%$ lower risk of CHD when compared with the consumption of less than three portions per $\mathrm{d}^{(2)}$. In an earlier meta-analysis, a $4 \%$ decrease in the risk of CHD has been found to be associated with each portion increase in fruit and vegetable intake ${ }^{(3)}$. However, substantial heterogeneities across studies were found in both reports, especially with regard to the association of vegetable intake with CHD risk. One possible explanation is that the types of fruits and vegetables commonly consumed and the processing methods used vary across study populations. Some specific groups of fruits and vegetables might have more benefits than others $^{(4,5)}$. The nutrient contents may differ in cooked $v$. raw vegetables $^{(6)}$. Furthermore, other dietary as well as lifestyle factors, such as saturated fat intake and smoking, which are correlated with fruit and vegetable intake, may modify the associations of fruit and vegetable intake with $\mathrm{CHD}$ risk $^{(4,7,8)}$

To date, most studies evaluating the association between fruit and vegetable intake and CHD risk have been conducted in the USA and Europe ${ }^{(2,9)}$. It remains unclear as to whether fruit and vegetable consumption is associated with CHD risk in Asian populations who generally have dietary patterns and cooking practices different from those of Western populations. In the present study, we investigated the association of fruit and vegetable consumption with $\mathrm{CHD}$ risk in two prospective cohorts of middle-aged and older Chinese men and women.

\section{Subjects and methods}

Participants of the Shanghai Women's Health Study (SWHS) and the Shanghai Men's Health Study (SMHS), two population-based prospective studies, were included in the present

Abbreviations: HR, hazard ratio; MI, myocardial infarction; SMHS, Shanghai Men's Health Study; SWHS, Shanghai Women's Health Study.

*Corresponding author: X. Zhang, fax +1 615936 8291, email xianglan.zhang@vanderbilt.edu 
analysis. The designs and methods have been described previously $^{(10,11)}$. In brief, 74941 women aged $40-70$ years were recruited from 1996 to 2000 and 61482 men aged 40-74 years were recruited from 2002 to 2006 in urban communities in Shanghai, China. Participation rates were 92.7 and $74 \cdot 1 \%$, respectively. In both studies, in-person interviews were conducted by trained staff using structured questionnaires to collect information on sociodemographics, diet and lifestyle habits, physical activities and medical history. Anthropometric measurements, including height and weight, were also taken at baseline. The present study was conducted according to the guidelines laid down in the Declaration of Helsinki, and all procedures involving human subjects were approved by the Institute Review Board of all institutes involved. Written informed consent was obtained from all the participants.

\section{Dietary assessment}

Food intakes were assessed using semi-quantitative FFQ in each cohort. The participants were asked, on average, how often they had consumed a specific food or food group during the preceding year and then how much they had consumed in grams per unit of time. Frequencies and amounts were converted into daily intake of each food. Total energy and nutrient intakes were calculated according to the 2002 Chinese Food Composition Tables ${ }^{(12)}$.

The validity and reproducibility of the questionnaires used for both cohorts were evaluated and found to be fairly high. Compared with twenty-four biweekly $24 \mathrm{~h}$ dietary recalls, the FFQ used in the SWHS covered $86 \%$ of the commonly consumed foods in the study population; the correlation coefficients between the estimates from the dietary recalls and those from the FFQ were 0.55 for total fruit intake and 0.41 for total vegetable intake ${ }^{(13)}$. Similarly, the FFQ used in the SMHS covered $89 \%$ of the recorded foods, and the correlation coefficients of dietary intake estimates derived from the FFQ and the average of twelve $24 \mathrm{~h}$ dietary recalls were 0.72 for total fruit intake and 0.42 for total vegetable intake ${ }^{(14)}$

Total fruit and vegetable intake was estimated by summing the intakes of all fruit and vegetable items. Fruit items listed in the FFQ in both the SMHS and SWHS included apple, pear, citrus fruit, banana, watermelon, peach, grape and other fruits (e.g. strawberry and cantaloupe). There were thirty-three vegetable items in the SWHS FFQ, including cruciferous vegetables (bok choy, cabbage, napa cabbage, cauliflower and white turnip), allium (garlic and garlic shoots, garlic bulb, onions, green onions and Chinese chives), legumes (fresh peas, fresh soyabeans, broad beans, Chinese long beans, green beans and snow peas) and other vegetables (celery, eggplant, cucumber, mushroom, tomato, sweet potato and bean sprouts). An expanded version of the SWHS FFQ was used in the SMHS, with the addition of four cruciferous vegetable items: garland chrysanthemum; shepherd's purse; clover; amaranth. Potatoes and dried beans were not included as vegetables due to their starchy content as suggested by the World Health Organization ${ }^{(15)}$.

\section{Outcome ascertainment}

Both cohorts were actively followed by in-person home visits, which took place every $2-3$ years, and annual linkage to vital statistics records. The overall follow-up rate was $96 \%$ for both cohorts. Very few cohort members moved out of the study area, and these participants were treated as censored observations, using date of the last contact as the censoring date. Our primary end point was incident CHD, comprising non-fatal myocardial infarction (MI) and fatal CHD. Selfreported diagnosis of MI was further confirmed through review of the participants' medical records by physicians who were unaware of their exposure status. Cases of MI were defined according to the WHO criteria: symptoms plus either diagnostic electrocardiographic changes or elevated levels of cardiac enzymes ${ }^{(16)}$.

In both cohorts, almost all the participants (99.9\%) were successfully followed for their vital status. Death due to CHD was determined by medical record review whenever possible and death certificates with CHD listed as the underlying cause of death (the International Classification of Diseases, 9th Revision, ICD-9 codes 410-414). In both the SWHS and SMHS, follow-up time was calculated from the date of baseline interview to the date of incident $\mathrm{CHD}$, death, loss to follow-up or 31 December 2009, whichever was first.

\section{Statistical analyses}

From the present study, we excluded 7618 women and 5804 men who reported a history of CHD, stroke or cancer at baseline (a history of cancer was an exclusion criterion for enrolment in the SMHS). We further excluded individuals with extreme energy intakes $(<2092$ or $>14644 \mathrm{~kJ} / \mathrm{d}$ for women $(n$ 112) and $<3347$ or $>17573 \mathrm{~kJ} / \mathrm{d}$ for men ( $n$ 204)). A total of 67211 women and 55474 men were included in the present analysis.

Analyses were carried out separately for each cohort in consideration of differences between the two cohorts in baseline characteristics of the participants, time period of recruitment and the duration of follow-up. Dietary intakes were adjusted for total energy using the residual method to control for confounding by total energy intake and reduce extraneous variations ${ }^{(17)}$. Pearson's partial correlation coefficients between total fruit and vegetable intake and related nutrients were calculated with adjustment for age, sex and energy intake. The participants were then classified by quartiles of energy-adjusted intakes of total fruits and vegetables. Baseline characteristics were compared using a $\chi^{2}$ test for categorical variables or linear regression for continuous variables. Hazard ratios (HR) and $95 \%$ CI were estimated by Cox proportional hazards regression models using age as timescale and stratified by birth cohort (5-year interval). In the SWHS, a multivariate model was adjusted for baseline age (continuous), BMI ( $\mathrm{kg} / \mathrm{m}^{2}$, continuous), family income (four categories), education level (four categories), smoking (since very few women ever smoked, dichotomous variable never/ever was used), alcohol consumption (never or ever, 
few women ever drank), physical activity level (quartiles of metabolic equivalent score, $\mathrm{h} /$ week $)^{(18)}$, use of aspirin and vitamin $\mathrm{E}$ and multivitamin supplements, menopausal status and hormone therapy (yes or no), total energy intake $(\mathrm{kJ} / \mathrm{d}$, continuous) and energy-adjusted intakes of red meat and fish/shellfish (g/d, continuous). In additional analyses, we further controlled for prior diagnoses of diabetes, hypertension or dyslipidaemia and nutrient intake (fibre, vitamin C, $\mathrm{K}$ or $\mathrm{Mg}$ ). Similar covariates were included in multivariate analyses of the SMHS cohort with refined categories for smoking (never, past or current: 1-9, 10-19 and $\geq 20$ cigarettes/d) and alcohol consumption (never, past or current: $<2$ and $\geq 2$ drinks/d). $P$ value for trend was assessed by treating the median value of each quartile as a continuous variable.

We also evaluated the HR of CHD associated with each portion increment in daily intake of fruits and vegetables, with a portion being defined as $80 \mathrm{~g}$ as suggested by the WHO and previous studies ${ }^{(15,19)}$. In addition, we applied restricted cubic spline regression with five knots (10th, 25th, 50th, 75th and 90th percentiles) to explore the dose-response relationships and potential optimal intakes ${ }^{(20)}$.

In addition, we examined the HR of CHD associated with specific types of fruits and vegetables, including apples and pears, bananas, citrus fruits, watermelon, other fruits, cruciferous vegetables, allium, legumes and other vegetables. A stratified analysis was carried out based on obesity status, physical activity level, smoking and the history of hypertension and diabetes. A sensitivity analysis was carried out by excluding the first 2 years of follow-up. Proportional hazards assumption was tested using the Schoenfeld residuals, and no significant violation was found. All statistical analyses were carried out using the SAS software (version 9.3; SAS Institute, Inc.), with a two-sided $P$ value $<0.05$ being considered statistically significant.

\section{Results}

The median intakes of total fruits and vegetables were 502 (interquartile range $360-673) \mathrm{g} / \mathrm{d}$ in the SWHS and 440 (interquartile range $315-590) \mathrm{g} / \mathrm{d}$ in the SMHS. Generally, women consumed more fruits but a slightly lower amount of vegetables than men (fruit median intake: $235 v .125 \mathrm{~g} / \mathrm{d}$; vegetable median intake: $250 v .295 \mathrm{~g} / \mathrm{d}$ ). In both studies, individuals who consumed more fruits and vegetables had higher income and education, were less likely to smoke and more likely to use aspirin or vitamin supplements (Table 1). They also had greater levels of physical activity, BMI and fish/ shellfish intake. The prevalence of diabetes and hypertension decreased across increasing quartiles of total fruit and vegetable intake in women but not in men. The intakes of several nutrients were highly correlated with total fruit and vegetable intake; partial Pearson's correlation coefficients were $0 \cdot 81$ for dietary fibre, 0.92 for vitamin C, 0.88 for $\mathrm{K}$ and 0.74 for $\mathrm{Mg}$.

During an average follow-up period of 9.8 years, 148 self-reported cases of CHD among women were confirmed by medical record review. After adjustment for potential confounding factors, including sociodemographic status, lifestyle and BMI, as well as total energy and red meat and fish intake, women in the highest quartile of total fruit and vegetable intake had a HR of 0.62 (95\% CI $0.38,1.02)$ for CHD ( $P$ for trend $=0.04$ ) compared with those in the lowest quartile (Table 2). The corresponding HR were 0.62 (95\% CI $0.37,1.03)$ for fruit intake and 0.94 (95\% CI $0.59,1.50)$ for vegetable intake. When we further controlled for prior history of diabetes, hypertension or dyslipidaemia, these inverse associations were attenuated with a HR of 0.67 (95\% CI $0 \cdot 41,1 \cdot 10 ; P$ for trend=0.09) comparing the extreme quartiles of total fruit and vegetable intake. Additional adjustment for dietary $\mathrm{K}$ or $\mathrm{Mg}$, but not for fibre or vitamin $\mathrm{C}$, also attenuated the inverse association (data not shown in the table).

In the SMHS, 217 cases were verified after a mean follow-up period of 5.4 years. No statistically significant association with CHD risk was found for fruits and vegetables when analysed either together or separately (Table 2).

To make a comparison with results of previous studies, we estimated standard portions of intake with one portion defined as $80 \mathrm{~g}$. Each portion increment in total fruit and vegetable intake was associated with a $6 \%$ reduction of incident CHD among women (HR 0.94, 95\% CI 0.89, 1.00, $P=0.05$; Table 2). The spline dose-response curves also suggested that the HR for CHD decreased with each portion increment in total fruit and vegetable intake for women (Fig. 1(a)). Compared with the consumption of three portions/d, the inverse association appeared to be evident only when the intake level reached at least eight portions/d (HR 0.69, 95\% CI $0.45,1.06)$. For men, the lowest HR for CHD occurred at approximately six portions per d (Fig. 1(b)).

Tables 3 and 4 report the HR of CHD associated with the major types of fruits and vegetables consumed by women and men, respectively. Higher banana intake was significantly associated with a lower risk of CHD in women, with a HR comparing the extreme quartiles of 0.48 (95\% CI 0.30 , 0.78; $P$ for trend=0.006). Although other types of fruits also exhibited inverse associations with CHD risk, none of these associations reached statistical significance. Similar to total vegetables, no significant association was found for specific types of vegetables evaluated in either women or men.

In the stratified analysis, the inverse association between total fruit and vegetable intake and CHD risk seemed to be stronger in overweight and physically inactive women. The HR for each portion $(80 \mathrm{~g})$ increment were 0.93 (95\% CI $0.86,1.00)$ and 0.98 (95\% CI 0.88, 1.09) for women with BMI $\geq 24 v .<24 \mathrm{~kg} / \mathrm{m}^{2}$ and $0.92(95 \%$ CI $0.84,1.02)$ and 0.96 (95\% CI $0.89,1.04$ ) for physically inactive $v$. active women. However, none of the interactions was significant. For men, no difference in the association due to BMI or physical activity was observed. For both men and women, no effect modification by smoking or history of hypertension or diabetes was found. The sensitivity analysis indicated no material changes in the results when the first 2 years of follow-up in both cohorts were omitted.

\section{Discussion}

In these two prospective cohorts of middle-aged and older Chinese adults, we evaluated the association between fruit 
Table 1. Baseline characteristics of the participants by quartiles of total fruit and vegetable intake*

(Mean values or percentages)

\begin{tabular}{|c|c|c|c|c|}
\hline \multirow[b]{2}{*}{ Characteristics } & \multicolumn{4}{|c|}{ Quartile } \\
\hline & Q1 (low) & Q2 & Q3 & Q4 \\
\hline \multicolumn{5}{|c|}{ Shanghai Women's Health Study ( $n 67211)$} \\
\hline Intake range $(\mathrm{g} / \mathrm{d})$ & $<360$ & $360-502$ & $502-673$ & $>673$ \\
\hline Age (years) & 53.9 & 51.9 & $51 \cdot 1$ & $50 \cdot 2$ \\
\hline High income† (\%) & $12 \cdot 9$ & $17 \cdot 0$ & $19 \cdot 6$ & $21 \cdot 6$ \\
\hline High education $\ddagger(\%)$ & $9 \cdot 6$ & $13 \cdot 6$ & $15 \cdot 4$ & $15 \cdot 5$ \\
\hline Ever smoking (\%) & 4.4 & $2 \cdot 4$ & 1.9 & 1.9 \\
\hline Alcohol consumption (\%) & $2 \cdot 3$ & $2 \cdot 1$ & $2 \cdot 1$ & $2 \cdot 4$ \\
\hline Postmenopausal (\%) & 54.4 & $45 \cdot 8$ & $43 \cdot 0$ & $39 \cdot 2$ \\
\hline Hormone therapy (\%) & $1 \cdot 3$ & 1.9 & $2 \cdot 2$ & 2.5 \\
\hline Aspirin use (\%) & 1.1 & 1.2 & 1.4 & 1.7 \\
\hline Vitamin E supplement use (\%) & $7 \cdot 3$ & $10 \cdot 0$ & $11 \cdot 3$ & $13 \cdot 3$ \\
\hline Multivitamin supplement use (\%) & 4.6 & $6 \cdot 7$ & $7 \cdot 7$ & $8 \cdot 7$ \\
\hline Baseline diabetes (\%) & $5 \cdot 8$ & 3.4 & $2 \cdot 8$ & $2 \cdot 1$ \\
\hline Baseline hypertension (\%) & $21 \cdot 4$ & $20 \cdot 0$ & $19 \cdot 3$ & 19.5 \\
\hline $\operatorname{BMI}\left(\mathrm{kg} / \mathrm{m}^{2}\right)$ & 23.9 & $23 \cdot 8$ & $23 \cdot 8$ & $24 \cdot 0$ \\
\hline Physical activity (MET-h/week) & 104.5 & $106 \cdot 2$ & $106 \cdot 8$ & $110 \cdot 4$ \\
\hline \multicolumn{5}{|l|}{ Dietary intake* } \\
\hline Total energy $(\mathrm{kJ} / \mathrm{d})$ & 6983 & 7100 & 7088 & 6945 \\
\hline Red meat $(\mathrm{g} / \mathrm{d})$ & 48 & 51 & 49 & 47 \\
\hline Fish and shellfish (g/d) & 36 & 46 & 53 & 62 \\
\hline Dietary fibre $(\mathrm{g} / \mathrm{d})$ & 8 & 10 & 11 & 14 \\
\hline Vitamin C $(\mathrm{mg} / \mathrm{d})$ & 47 & 72 & 95 & 141 \\
\hline $\mathrm{K}(\mathrm{mg} / \mathrm{d})$ & 1289 & 1578 & 1813 & 2243 \\
\hline $\mathrm{Mg}(\mathrm{mg} / \mathrm{d})$ & 233 & 256 & 275 & 310 \\
\hline \multicolumn{5}{|l|}{ Shanghai Men's Health Study ( $n 55474$ ) } \\
\hline Intake range $(\mathrm{g} / \mathrm{d})$ & $<316$ & $316-440$ & $440-590$ & $>590$ \\
\hline Age (years) & 54.4 & 54.4 & 54.5 & 54.5 \\
\hline High incomet (\%) & $6 \cdot 3$ & 8.6 & $10 \cdot 6$ & $14 \cdot 0$ \\
\hline High education $\ddagger(\%)$ & $15 \cdot 7$ & $21 \cdot 0$ & $25 \cdot 4$ & $30 \cdot 0$ \\
\hline \multicolumn{5}{|l|}{ Smoking (\%) } \\
\hline Never & 21.5 & 27.9 & 32.5 & $36 \cdot 6$ \\
\hline Past & $8 \cdot 3$ & $9 \cdot 2$ & 9.9 & $10 \cdot 5$ \\
\hline Current & $70 \cdot 2$ & 62.9 & $57 \cdot 6$ & 52.9 \\
\hline \multicolumn{5}{|l|}{ Alcohol consumption (\%) } \\
\hline Never & $63 \cdot 2$ & $66 \cdot 6$ & $67 \cdot 3$ & $67 \cdot 7$ \\
\hline Past & $4 \cdot 2$ & $3 \cdot 8$ & 3.6 & 3.6 \\
\hline Current & $32 \cdot 6$ & $29 \cdot 6$ & $29 \cdot 1$ & $28 \cdot 7$ \\
\hline Aspirin use (\%) & $2 \cdot 4$ & $3 \cdot 3$ & $4 \cdot 0$ & 5.5 \\
\hline Vitamin E supplement use (\%) & $2 \cdot 3$ & 3.5 & 4.3 & $6 \cdot 0$ \\
\hline Multivitamin supplement use (\%) & $5 \cdot 0$ & $6 \cdot 7$ & $7 \cdot 9$ & $10 \cdot 0$ \\
\hline Baseline diabetes (\%) & $5 \cdot 3$ & 5.4 & $5 \cdot 1$ & 5.5 \\
\hline Baseline hypertension (\%) & $24 \cdot 3$ & $25 \cdot 7$ & $26 \cdot 1$ & $28 \cdot 3$ \\
\hline $\mathrm{BMI}\left(\mathrm{kg} / \mathrm{m}^{2}\right)$ & $23 \cdot 3$ & $23 \cdot 6$ & $23 \cdot 7$ & 24.0 \\
\hline Physical activity (MET-h/week) & $56 \cdot 0$ & $58 \cdot 2$ & $60 \cdot 3$ & $62 \cdot 7$ \\
\hline \multicolumn{5}{|l|}{ Dietary intake* } \\
\hline Total energy $(\mathrm{kJ} / \mathrm{d})$ & 8033 & 8109 & 8067 & 7954 \\
\hline Red meat $(\mathrm{g} / \mathrm{d})$ & 61 & 62 & 62 & 60 \\
\hline Fish and shellfish $(\mathrm{g} / \mathrm{d})$ & 38 & 47 & 54 & 64 \\
\hline Dietary fibre $(\mathrm{g} / \mathrm{d})$ & 9 & 10 & 12 & 15 \\
\hline Vitamin C $(\mathrm{mg} / \mathrm{d})$ & 50 & 78 & 101 & 150 \\
\hline $\mathrm{K}(\mathrm{mg} / \mathrm{d})$ & 1430 & 1723 & 1965 & 2422 \\
\hline $\mathrm{Mg}(\mathrm{mg} / \mathrm{d})$ & 271 & 298 & 321 & 363 \\
\hline
\end{tabular}

MET, metabolic equivalents.

* Intake values were energy adjusted using the residual method. $P$ values were all $<0.005$ (except for alcohol consumption in women $(P=0.14)$, age in men $(P=0.71)$ and diabetes in men $(P=0.36))$.

$\dagger$ High income was defined as family income $\geq 30000$ yuan per year for women or personal income $\geq 2000$ yuan per month for men.

$\ddagger$ High education was defined as professional or college education or more.

and vegetable intake and CHD risk. We found that each $80 \mathrm{~g} / \mathrm{d}$ increase in total fruit and vegetable consumption was associated with a $6 \%$ decrease in CHD incidence in women; this inverse association was primarily driven by fruit intake. In men, the link between fruit or vegetable intake and reduced risk of CHD was less evident.
The cardioprotective effect of fruits and vegetables might be mediated through several established CVD risk factors, such as hypertension, hypercholesterolaemia and diabetes ${ }^{(1)}$. This is suggested by the findings of the present study and previous studies that the inverse associations between fruit and vegetable intake and CHD risk are attenuated when history of 
Table 2. Hazard ratios (HR) of incident CHD by fruit and vegetable intake (Hazard ratios and $95 \%$ confidence intervals)

\begin{tabular}{|c|c|c|c|c|c|c|c|c|c|c|c|}
\hline & \multicolumn{7}{|c|}{ Quartile } & \multirow[b]{3}{*}{$P$ for trend } & \multirow{2}{*}{\multicolumn{3}{|c|}{ Per $80 \mathrm{~g} / \mathrm{d}$ increase }} \\
\hline & \multirow{2}{*}{$\frac{\mathrm{Q} 1}{\mathrm{HR}}$} & \multicolumn{2}{|r|}{ Q2 } & \multicolumn{2}{|r|}{ Q3 } & \multicolumn{2}{|r|}{ Q4 } & & & & \\
\hline & & $\mathrm{HR}$ & $95 \% \mathrm{Cl}$ & $\mathrm{HR}$ & $95 \% \mathrm{Cl}$ & $\mathrm{HR}$ & $95 \% \mathrm{Cl}$ & & $\mathrm{HR}$ & $95 \% \mathrm{Cl}$ & $P$ \\
\hline \multicolumn{12}{|c|}{ Shanghai Women's Health Study } \\
\hline \\
\hline Median intake $(\mathrm{g} / \mathrm{d})^{\star}$ & 274 & & 432 & & 581 & & 814 & & & & \\
\hline Cases $(n)$ & 60 & & 35 & & 29 & & 24 & & & & \\
\hline Model $1 \dagger$ & 1 & 0.74 & $0.48,1.12$ & 0.68 & $0.43,1.07$ & 0.62 & $0.38,1.02$ & 0.04 & 0.94 & $0.89,1.00$ & 0.05 \\
\hline Model $2 \ddagger$ & 1 & 0.77 & $0.50,1 \cdot 18$ & 0.71 & $0.45,1.13$ & 0.67 & $0.41,1.10$ & 0.09 & 0.95 & $0.90,1.01$ & $0 \cdot 12$ \\
\hline \multicolumn{12}{|l|}{ All fruits } \\
\hline Median intake $(\mathrm{g} / \mathrm{d})^{\star}$ & 83 & & 188 & & 287 & & 449 & & & & \\
\hline Cases $(n)$ & 57 & & 37 & & 33 & & 21 & & & & \\
\hline Model $1 \dagger$ & 1 & 0.87 & $0.57,1.33$ & 0.87 & $0.56,1.36$ & 0.62 & $0.37,1.03$ & 0.08 & 0.88 & $0.80,0.97$ & 0.009 \\
\hline Model 2ł & 1 & 1.01 & $0.66,1.55$ & 1.06 & $0.68,1.67$ & 0.77 & $0.45,1.31$ & 0.42 & 0.93 & $0.84,1.02$ & $0 \cdot 11$ \\
\hline \multicolumn{12}{|l|}{ All vegetables } \\
\hline Median intake $(\mathrm{g} / \mathrm{d})^{\star}$ & 137 & & 213 & & 292 & & 429 & & & & \\
\hline Cases $(n)$ & 43 & & 43 & & 29 & & 33 & & & & \\
\hline Model $1 \dagger$ & 1 & $1 \cdot 18$ & $0.77,1.81$ & 0.84 & $0.52,1.35$ & 0.94 & $0.58,1.50$ & 0.52 & 0.99 & $0.90,1.08$ & 0.76 \\
\hline Model $2 \ddagger$ & 1 & $1 \cdot 15$ & $0.75,1 \cdot 76$ & 0.77 & $0.48,1 \cdot 25$ & 0.83 & $0.52,1.33$ & 0.24 & 0.96 & $0.87,1.05$ & 0.37 \\
\hline \multicolumn{12}{|c|}{ Shanghai Men's Health Study } \\
\hline \multicolumn{12}{|c|}{ Total fruits and vegetables } \\
\hline Median intake $(\mathrm{g} / \mathrm{d})^{\star}$ & 242 & & 379 & & 507 & & 722 & & & & \\
\hline Cases $(n)$ & 65 & & 51 & & 47 & & 54 & & & & \\
\hline Model $1 \dagger$ & 1 & 0.80 & $0.55,1 \cdot 16$ & 0.75 & $0.51,1 \cdot 10$ & 0.85 & $0.58,1.25$ & 0.45 & 0.99 & $0.94,1.04$ & 0.75 \\
\hline Model $2 \ddagger$ & 1 & 0.80 & $0.55,1.16$ & 0.76 & $0.51,1.11$ & 0.86 & $0.59,1.26$ & 0.49 & 0.99 & $0.94,1.05$ & 0.80 \\
\hline \multicolumn{12}{|l|}{ All fruits } \\
\hline Median intake $(\mathrm{g} / \mathrm{d})^{\star}$ & 23 & & 90 & & 162 & & 285 & & & & \\
\hline Cases $(n)$ & 57 & & 57 & & 51 & & 52 & & & & \\
\hline Model $1 \dagger$ & 1 & 0.95 & $0.66,1.39$ & 0.85 & $0.57,1.25$ & 0.86 & $0.57,1.28$ & 0.40 & 0.94 & $0.85,1.03$ & 0.20 \\
\hline Model $2 \ddagger$ & 1 & 1.01 & $0.69,1.47$ & 0.93 & $0.62,1.38$ & 0.96 & $0.63,1.44$ & 0.77 & 0.96 & $0.88,1.06$ & 0.44 \\
\hline \multicolumn{12}{|l|}{ All vegetables } \\
\hline Median intake $(\mathrm{g} / \mathrm{d})^{*}$ & 160 & & 253 & & 344 & & 502 & & & & \\
\hline Cases $(n)$ & 61 & & 55 & & 40 & & 61 & & & & \\
\hline Model $1 \dagger$ & 1 & 0.96 & $0.67,1.39$ & 0.69 & $0.46,1.04$ & 1.07 & $0.74,1.55$ & 0.84 & 1.02 & $0.96,1.09$ & 0.53 \\
\hline Model 2ł & 1 & 0.95 & $0.65,1.37$ & 0.68 & $0.45,1.01$ & 1.02 & $0.71,1.48$ & 0.96 & 1.01 & $0.95,1.08$ & 0.73 \\
\hline
\end{tabular}

* Intake values were energy adjusted using the residual method.

† Model was stratified by birth cohort (5-year interval) and adjusted for baseline age, BMI, income, education, smoking, alcohol consumption, physical activity, use of aspirin and vitamin $\mathrm{E}$ and multivitamin supplements (in only women: menopause and hormone replacement therapy), total energy, and red meat and fish/shellfish intake. $\ddagger$ Further adjusted for history of diabetes, hypertension or dyslipidaemia.

hypertension or diabetes is controlled for ${ }^{(21)}$. Randomised controlled trials have shown that an increased consumption of fruits and vegetables significantly reduces blood pressure $^{(22,23)}$, perhaps due to the high $\mathrm{K}$ and $\mathrm{Mg}$ contents of fruits and vegetables. Also, the high levels of fibre ${ }^{(24)}$, plant phytosterols ${ }^{(25)}$ and vitamins ${ }^{(26)}$ present in fruits and vegetables may reduce blood cholesterol levels, oxidative stress and inflammation. In the study population, the intakes of $\mathrm{K}$, $\mathrm{Mg}$, dietary fibre and vitamin $\mathrm{C}$ were highly correlated with total fruit and vegetable intake. Additional adjustment for $\mathrm{K}$ or $\mathrm{Mg}$ largely diminished the inverse association of total fruit and vegetable intake with $\mathrm{CHD}$ risk observed in the present study. It is plausible that the high $\mathrm{K}$ and $\mathrm{Mg}$ contents in bananas might partially explain our finding of an inverse association between banana intake and CHD risk in women and a recent report of an inverse association of banana intake with blood pressure in Asian adults ${ }^{(27)}$.

The association of fruit and vegetable intake with CHD risk observed in the SWHS is consistent with previous results in both direction and magnitude. So far, many prospective studies have been conducted among Western populations. In the Women's Health Study of 39127 middle-aged US female health professionals, the relative risks of MI across extreme quintiles were $0.62(95 \% \mathrm{CI} 0.37,1.04)$ for total fruits and vegetables and 0.57 (95\% CI $0.34,0.98)$ for all fruits $^{(21)}$. Similar to that observed in the present study, after additional adjustment for CHD risk factors, including history of diabetes, hypertension and high cholesterol levels, the inverse associations became statistically non-significant. In the Nurses' Health Study, Joshipura et al. ${ }^{(28)}$ found that one serving/d increase in fruit and vegetable intake was associated with a $4 \%$ decreased risk of CHD. Data from Asian populations are limited. In the Japan Public Health Center-based Prospective Study, the consumption of fruits, but not of vegetables, was inversely associated with $\mathrm{CVD}$ incidence (including MI and stroke) ${ }^{(29)}$. In another Japanese cohort, a higher intake of fruits and vegetables was associated with a lower risk of death from CVD only in Japanese women but not in men ${ }^{(30)}$. 

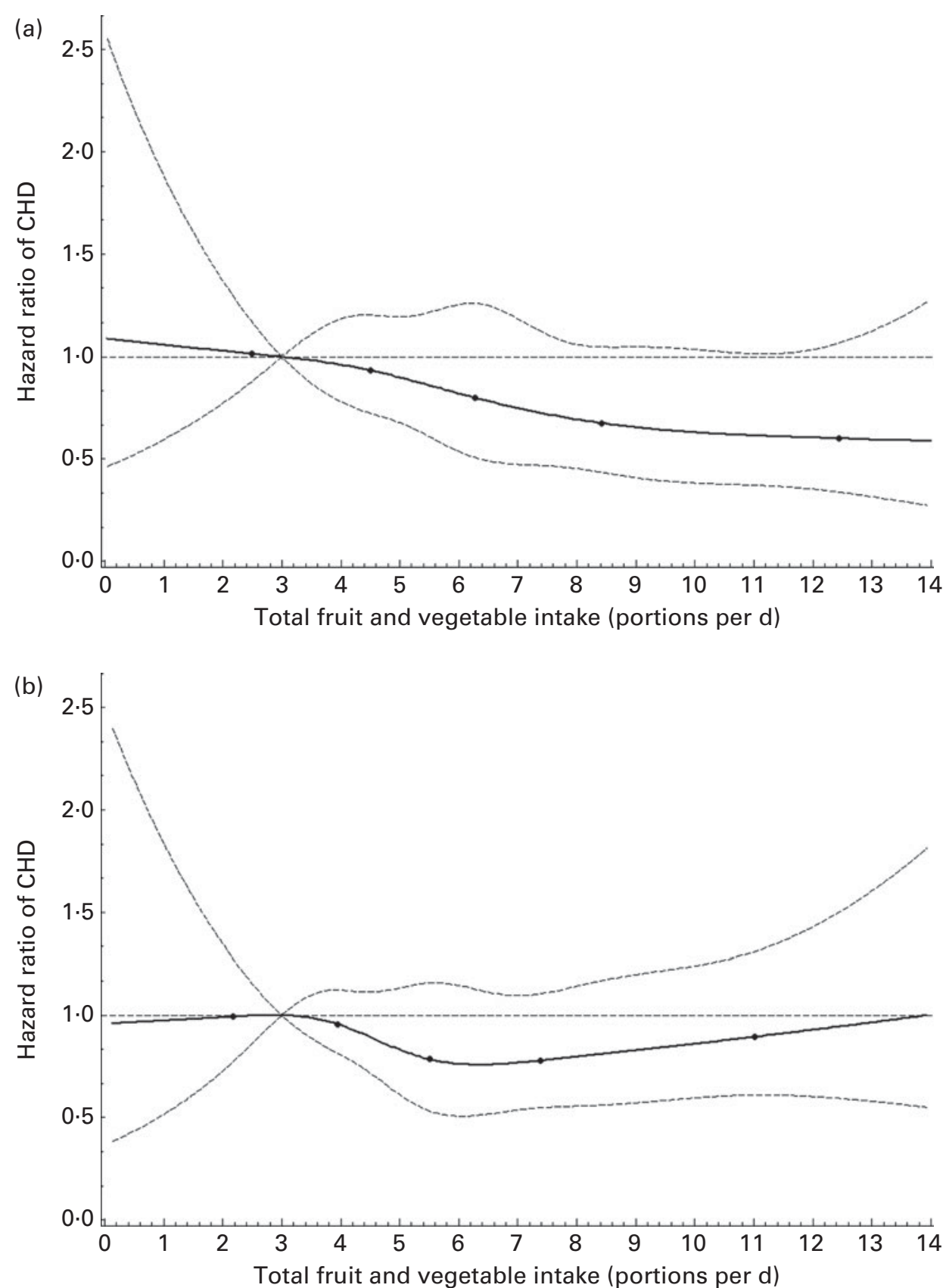

Fig. 1. Dose-response relationships between total fruit and vegetable intake and CHD risk by restricted cubic spline analysis in Chinese (a) women and (b) men ( - , hazard ratio; ----, $95 \% \mathrm{Cl}$; reference: three portions/d).

As indicated in the present study and some previous studies, the inverse association with CHD risk was less consistent for vegetable intake than for fruit intake ${ }^{(2,3)}$. For example, total vegetable intake was not associated with MI incidence among US male physicians ${ }^{(31)}$ or Italian women ${ }^{(32)}$, although leafy vegetables and olive oil exhibited significant inverse associations in the latter study. In Finnish male smokers ${ }^{(33)}$ and in Japanese women, but not in men ${ }^{(30)}$, higher vegetable intake was associated with a lower risk of non-fatal MI or CHD death. The heterogeneity might arise from differences in commonly consumed vegetables and other dietary factors and variation in traditional cooking methods across nations.
In general, Chinese people, particularly the older generation such as the participants in the present study, prefer cooked vegetables rather than raw vegetables, and the most commonly used cooking methods are stir-frying and boiling. Such methods of processing vegetables may lead to the loss of water-soluble, heat-sensitive and oxygen-labile nutrients $^{(34)}$. In addition, salt is typically added during home cooking, and this may offset the benefits of vegetables ${ }^{(35)}$. Fruits are typically eaten raw by the study population and fruit juice consumption is likely to be negligible ${ }^{(27)}$. The association of vegetable intake with CHD risk might also be modified by other dietary factors. Some studies have 
Table 3. Hazard ratios (HR) of incident CHD by types of fruits and vegetables in the Shanghai Women's Health Study

(Hazard ratios and $95 \%$ confidence intervals)

\begin{tabular}{|c|c|c|c|c|c|c|c|c|}
\hline & \multicolumn{7}{|c|}{ Quartile } & \multirow[b]{3}{*}{$P$ for trend } \\
\hline & \multirow{2}{*}{$\frac{\mathrm{Q} 1}{\mathrm{HR}}$} & \multicolumn{2}{|r|}{ Q2 } & \multicolumn{2}{|c|}{ Q3 } & \multicolumn{2}{|c|}{ Q4 } & \\
\hline & & $\mathrm{HR}$ & $95 \% \mathrm{Cl}$ & $\mathrm{HR}$ & $95 \% \mathrm{Cl}$ & $\mathrm{HR}$ & $95 \% \mathrm{Cl}$ & \\
\hline \multicolumn{9}{|l|}{ Types of fruits } \\
\hline \multicolumn{9}{|l|}{ Apples and pears } \\
\hline Median intake $(\mathrm{g} / \mathrm{d})^{*}$ & $10 \cdot 1$ & \multirow{2}{*}{\multicolumn{2}{|c|}{$\begin{array}{c}41.9 \\
33\end{array}$}} & \multicolumn{2}{|c|}{$78 \cdot 6$} & \multicolumn{2}{|c|}{$138 \cdot 6$} & \\
\hline Cases $(n)$ & 58 & & & \multicolumn{2}{|c|}{28} & \multicolumn{2}{|c|}{29} & \\
\hline Model $1 \dagger$ & 1 & 0.77 & $0.50,1.18$ & 0.67 & $0.42,1.07$ & 0.77 & $0.49,1.24$ & 0.23 \\
\hline Model $2 \ddagger$ & 1 & 0.83 & $0.53,1.28$ & 0.76 & $0.48,1.21$ & 0.92 & $0.57,1.48$ & 0.65 \\
\hline \multicolumn{9}{|l|}{ Bananas } \\
\hline Median intake $(\mathrm{g} / \mathrm{d})^{*}$ & 0.2 & \multirow{2}{*}{\multicolumn{2}{|c|}{$\begin{array}{c}3 \cdot 3 \\
36\end{array}$}} & \multicolumn{2}{|c|}{$11 \cdot 3$} & \multicolumn{2}{|c|}{$37 \cdot 9$} & \\
\hline Cases $(n)$ & 59 & & & & & & & \\
\hline Model $1 \dagger$ & 1 & 0.75 & $0.49,1.14$ & 0.63 & $0.40,0.99$ & 0.48 & $0.30,0.78$ & 0.006 \\
\hline Model $2 \ddagger$ & 1 & 0.93 & $0.60,1.44$ & 0.79 & $0.49,1.26$ & 0.60 & $0.37,1.00$ & 0.045 \\
\hline \multicolumn{9}{|l|}{ Citrus fruits } \\
\hline Median intake $(\mathrm{g} / \mathrm{d})^{*}$ & 1.5 & \multirow{2}{*}{\multicolumn{2}{|c|}{$\begin{array}{c}11 \cdot 0 \\
26\end{array}$}} & & & & & \\
\hline Cases $(n)$ & 60 & & & & & & & \\
\hline Model $1 \dagger$ & 1 & 0.58 & $0.36,0.92$ & 0.65 & $0.41,1.02$ & 0.74 & $0.48,1.15$ & 0.30 \\
\hline Model $2 \ddagger$ & 1 & 0.66 & $0.41,1.05$ & 0.75 & $0.48,1.19$ & 0.88 & $0.56,1.38$ & 0.77 \\
\hline Watermelon & & & & & & & & \\
\hline Median intake $(\mathrm{g} / \mathrm{d})^{\star}$ & 23.2 & & $72 \cdot 5$ & & & & & \\
\hline Cases $(n)$ & 54 & & 45 & & & & & \\
\hline Model $1 \dagger$ & 1 & 1.04 & $0.70,1.56$ & 0.74 & $0.46,1.17$ & 0.57 & $0.34,0.96$ & 0.02 \\
\hline Model $2 \ddagger$ & 1 & $1 \cdot 24$ & $0.82,1.87$ & 0.90 & $0.56,1.44$ & 0.71 & $0.42,1.20$ & 0.13 \\
\hline Other fruits & & & & & & & & \\
\hline Median intake $(\mathrm{g} / \mathrm{d})^{\star}$ & 1.5 & & $12 \cdot 2$ & & & & & \\
\hline Cases $(n)$ & 58 & & 38 & & & & & \\
\hline Model $1 \dagger$ & 1 & 0.93 & $0.61,1.41$ & 0.68 & $0.42,1 \cdot 10$ & 0.80 & $0.50,1.29$ & 0.33 \\
\hline Model $2 \ddagger$ & 1 & 1.03 & $0.68,1.58$ & 0.77 & $0.48,1.26$ & 0.94 & $0.58,1.51$ & 0.67 \\
\hline Types of vegetables & & & & & & & & \\
\hline Cruciferous vegetables & & & & & & & & \\
\hline Median intake $(\mathrm{g} / \mathrm{d})^{\star}$ & 32.9 & & $65 \cdot 6$ & & & & & \\
\hline Cases $(n)$ & 41 & & 34 & & & & & \\
\hline Model $1 \dagger$ & 1 & 0.87 & $0.55,1.37$ & 0.92 & $0.58,1.44$ & 0.88 & $0.56,1.38$ & 0.66 \\
\hline Model $2 \ddagger$ & 1 & 0.86 & $0.55,1.36$ & 0.90 & $0.57,1.42$ & 0.80 & $0.51,1.26$ & 0.38 \\
\hline Allium & & & & & & & & \\
\hline Median intake $(\mathrm{g} / \mathrm{d})^{\star}$ & 1.9 & & 4.2 & & & & & \\
\hline Cases $(n)$ & 37 & & 32 & & & & & \\
\hline Model 1† & 1 & 0.93 & $0.58,1.50$ & 1.09 & $0.69,1.74$ & 1.30 & $0.83,2.04$ & 0.15 \\
\hline Model $2 \ddagger$ & 1 & 0.92 & $0.57,1.49$ & 1.09 & $0.69,1.73$ & 1.27 & $0.81,1.99$ & 0.18 \\
\hline Legumes & & & & & & & & \\
\hline Median intake $(\mathrm{g} / \mathrm{d})^{\star}$ & 8.5 & & $17 \cdot 7$ & & & & & \\
\hline Cases $(n)$ & 45 & & 32 & & & & & \\
\hline Model 1† & 1 & 0.83 & $0.52,1.30$ & 0.90 & $0.58,1.39$ & 0.72 & $0.46,1.13$ & 0.19 \\
\hline Model $2 \ddagger$ & 1 & 0.80 & $0.51,1.26$ & 0.88 & $0.56,1.36$ & 0.69 & $0.44,1.09$ & 0.15 \\
\hline Other vegetables & & & & & & & & \\
\hline Median intake $(\mathrm{g} / \mathrm{d})^{\star}$ & $59 \cdot 6$ & & $104 \cdot 3$ & & & & & \\
\hline Cases $(n)$ & 49 & & 30 & & & & & \\
\hline Model 1† & 1 & 0.81 & $0.51,1.29$ & $1 \cdot 12$ & $0.73,1.74$ & 0.97 & $0.61,1.56$ & 0.84 \\
\hline Model 2‡ & 1 & 0.80 & $0.50,1.26$ & 1.06 & $0.69,1.65$ & 0.86 & $0.54,1.38$ & 0.75 \\
\hline
\end{tabular}

* Intake values were energy adjusted using the residual method.

† Model was stratified by birth cohort (5-year interval) and adjusted for baseline age, BMI, income, education, smoking, alcohol consumption, physical activity, use of aspirin and vitamin $\mathrm{E}$ and multivitamin supplements (in only women: menopause and hormone replacement therapy), total energy, and red meat and fish/shellfish intake.

¥ Further adjusted for history of diabetes, hypertension or dyslipidaemia.

suggested that the cardioprotective effect of vegetables is more pronounced when combined with a diet low in carbohydrates $^{(8)}$ or high in fats ${ }^{(7,36)}$. However, the traditional Chinese diet is featured by a high-carbohydrate and lowfat composition. In the study population, carbohydrate, total fat and saturated fat, respectively, accounted for 68,15 and $4.5 \%$ of total energy, compared with approximately 45 , 35 and $10 \%$ of total energy in a US population ${ }^{(37)}$. Vegetable intake was relatively high in the study population (median: 3.5 portions/d $v .<2$ portions/d in the USA and North Europe ${ }^{(9,38)}$; the median for the lowest quartile in the present study was approximately two portions/d). The overall high consumption, limited consumption variability and relatively low incidence of CHD might have contributed to the less consistent association between vegetable intake and CHD risk in the present study ${ }^{(39)}$.

As with most nutritional epidemiological studies, dietary assessment error is the main concern of the present study. 
Table 4. Hazard ratios (HR) of incident CHD by types of fruits and vegetables in the Shanghai Men's Health Study (Hazard ratios and $95 \%$ confidence intervals)

\begin{tabular}{|c|c|c|c|c|c|c|c|c|}
\hline & \multicolumn{7}{|c|}{ Quartile } & \multirow[b]{3}{*}{$P$ for trend } \\
\hline & \multirow{2}{*}{$\frac{\mathrm{Q} 1}{\mathrm{HR}}$} & \multicolumn{2}{|r|}{ Q2 } & \multicolumn{2}{|r|}{ Q3 } & \multicolumn{2}{|r|}{ Q4 } & \\
\hline & & $\mathrm{HR}$ & $95 \% \mathrm{Cl}$ & $\mathrm{HR}$ & $95 \% \mathrm{Cl}$ & $\mathrm{HR}$ & $95 \% \mathrm{Cl}$ & \\
\hline \multicolumn{9}{|l|}{ Types of fruits } \\
\hline \multicolumn{9}{|l|}{ Apples and pears } \\
\hline Median intake $(\mathrm{g} / \mathrm{d})^{*}$ & 0.01 & & $11 \cdot 1$ & & 31.5 & & $78 \cdot 8$ & \\
\hline Cases $(n)$ & 61 & & 50 & & 58 & & 48 & \\
\hline Model $1 \dagger$ & 1 & 0.81 & $0.55,1.18$ & 0.91 & $0.63,1.32$ & 0.70 & $0.47,1.05$ & 0.14 \\
\hline Model $2 \ddagger$ & 1 & 0.84 & $0.57,1.24$ & 0.96 & $0.66,1.40$ & 0.75 & $0.50,1.13$ & 0.24 \\
\hline \multicolumn{9}{|l|}{ Bananas } \\
\hline Median intake $(\mathrm{g} / \mathrm{d})^{\star}$ & 0 & & $1 \cdot 6$ & & 4.9 & & $17 \cdot 3$ & \\
\hline Cases $(n)$ & 64 & & 45 & & 49 & & 59 & \\
\hline Model $1 \dagger$ & 1 & 0.73 & $0.50,1.08$ & 0.76 & $0.53,1.11$ & 0.85 & $0.59,1.23$ & 0.86 \\
\hline Model $2 \ddagger$ & 1 & 0.83 & $0.55,1.24$ & 0.87 & $0.59,1.30$ & 0.97 & $0.66,1.43$ & 0.74 \\
\hline \multicolumn{9}{|l|}{ Citrus fruits } \\
\hline Median intake $(\mathrm{g} / \mathrm{d})^{*}$ & 0 & & 3.5 & & $10 \cdot 0$ & & $27 \cdot 3$ & \\
\hline Cases $(n)$ & 65 & & 48 & & 55 & & 49 & \\
\hline Model $1 \dagger$ & 1 & 0.74 & $0.51,1.07$ & 0.83 & $0.57,1.20$ & 0.69 & $0.47,1.02$ & 0.15 \\
\hline Model $2 \ddagger$ & 1 & 0.77 & $0.53,1.13$ & 0.88 & $0.60,1.27$ & 0.74 & $0.50,1.09$ & 0.24 \\
\hline \multicolumn{9}{|l|}{ Watermelon } \\
\hline Median intake $(\mathrm{g} / \mathrm{d})^{*}$ & 4.7 & & $37 \cdot 1$ & & $81 \cdot 3$ & & $167 \cdot 5$ & \\
\hline Cases $(n)$ & 67 & & 48 & & 45 & & 57 & \\
\hline Model $1 \dagger$ & 1 & 0.71 & $0.48,1.03$ & 0.66 & $0.45,0.97$ & 0.86 & $0.60,1.25$ & 0.69 \\
\hline Model $2 \ddagger$ & 1 & 0.75 & $0.52,1 \cdot 10$ & 0.73 & $0.49,1.07$ & 0.96 & $0.66,1.41$ & 0.85 \\
\hline \multicolumn{9}{|l|}{ Other fruits } \\
\hline Median intake $(\mathrm{g} / \mathrm{d})^{*}$ & 0 & & $5 \cdot 8$ & & $13 \cdot 3$ & & $33 \cdot 1$ & \\
\hline Cases $(n)$ & 76 & & 43 & & 50 & & 48 & \\
\hline Model $1 \dagger$ & 1 & 0.57 & $0.39,0.83$ & 0.66 & $0.46,0.95$ & 0.63 & $0.43,0.92$ & 0.09 \\
\hline Model $2 \ddagger$ & 1 & 0.59 & $0.40,0.86$ & 0.69 & $0.48,0.99$ & 0.65 & $0.44,0.95$ & 0.11 \\
\hline \multicolumn{9}{|l|}{ Types of vegetables } \\
\hline \multicolumn{9}{|l|}{ Cruciferous vegetables } \\
\hline Median intake $(\mathrm{g} / \mathrm{d})^{\star}$ & 39.5 & & $76 \cdot 3$ & & $115 \cdot 5$ & & $186 \cdot 4$ & \\
\hline Cases $(n)$ & 51 & & 57 & & 48 & & 61 & \\
\hline Model $1 \dagger$ & 1 & $1 \cdot 14$ & $0.78,1.67$ & 0.96 & $0.64,1.43$ & $1 \cdot 17$ & $0.80,1 \cdot 70$ & 0.55 \\
\hline Model $2 \ddagger$ & 1 & $1 \cdot 12$ & $0.76,1.63$ & 0.94 & $0.63,1.40$ & $1 \cdot 13$ & $0.78,1.65$ & 0.66 \\
\hline \multicolumn{9}{|l|}{ Allium } \\
\hline Median intake $(\mathrm{g} / \mathrm{d})^{*}$ & 4.7 & & $9 \cdot 2$ & & $15 \cdot 1$ & & 28.5 & \\
\hline Cases $(n)$ & 64 & & 46 & & 53 & & 54 & \\
\hline Model $1 \dagger$ & 1 & 0.74 & $0.51,1.08$ & 0.86 & $0.60,1.25$ & 0.89 & $0.61,1.29$ & 0.86 \\
\hline Model $2 \ddagger$ & 1 & 0.74 & $0.50,1.08$ & 0.85 & $0.59,1.23$ & 0.86 & $0.60,1.25$ & 0.75 \\
\hline \multicolumn{9}{|l|}{ Legumes } \\
\hline Median intake $(\mathrm{g} / \mathrm{d})^{\star}$ & $10 \cdot 8$ & & $22 \cdot 8$ & & 35.8 & & $62 \cdot 8$ & \\
\hline Cases $(n)$ & 61 & & 45 & & 58 & & 53 & \\
\hline Model 1† & 1 & 0.76 & $0.52,1.13$ & 0.99 & $0.69,1.42$ & 0.92 & $0.63,1.34$ & 0.99 \\
\hline Model 2ł & 1 & 0.78 & $0.53,1.15$ & 1.00 & $0.70,1.44$ & 0.94 & $0.65,1.37$ & 0.92 \\
\hline \multicolumn{9}{|l|}{ Other vegetables } \\
\hline Median intake $(\mathrm{g} / \mathrm{d})^{*}$ & $68 \cdot 3$ & & $118 \cdot 0$ & & $170 \cdot 0$ & & $270 \cdot 2$ & \\
\hline Cases $(n)$ & 68 & & 50 & & 40 & & 59 & \\
\hline Model $1 \dagger$ & 1 & 0.79 & $0.55,1.14$ & 0.65 & $0.44,0.97$ & 0.96 & $0.67,1.39$ & 0.95 \\
\hline Model $2 \ddagger$ & 1 & 0.79 & $0.54,1.14$ & 0.63 & $0.42,0.94$ & 0.91 & $0.63,1.31$ & 0.70 \\
\hline
\end{tabular}

*Intake values were energy adjusted using the residual method.

† Model was stratified by birth cohort (5-year interval) and adjusted for baseline age, BMI, income, education, smoking, alcohol consumption, physical activity, use of aspirin and vitamin $\mathrm{E}$ and multivitamin supplements (in only women: menopause and hormone replacement therapy), total energy, and red meat and fish/shellfish intake.

$\ddagger$ Further adjusted for history of diabetes, hypertension or dyslipidaemia.

Compared with the assessment of fruit intake, that of vegetable intake is more challenging because of the large variety of vegetables and the difficulty in estimating portions. As indicated in our validation studies, vegetable intake was assessed less accurately than fruit intake ${ }^{(13,14)}$, and this may further explain the less consistent results that we obtained for vegetables. A Japanese cohort study has also suggested that men might report their intake less accurately than women ${ }^{(30)}$.
In addition to measurement error, the relatively short follow-up duration in the men's cohort could also have reduced our ability to detect significant associations. Because of the shorter follow-up period, changes in diets due to the presence of risk factors or subclinical diseases (reverse causation bias) might have had a greater influence on the results of men than on those of women. Another concern of the study is residual confounding, even though we 
extensively controlled for potential confounders, including socio-economic status, BMI, physical activity, smoking and other established risk factors of CHD. Fruit and vegetable intake is, in general, associated with a healthy lifestyle and likely to be included as part of a healthy dietary pattern. We adjusted for several important lifestyle and dietary variables in multivariable analyses and conducted analyses stratified by smoking, physical activity and BMI to further evaluate the independent association between fruit and vegetable intake and CHD risk and potential effect modifications. We found no evidence of significant effect modifications. Nevertheless, we cannot exclude the possibility of residual confounding or effect modifications by other unmeasured covariates. Finally, the participants were recruited from urban Shanghai, the most developed region in China, so the results may not be entirely generalisable to Chinese people living in other areas or other countries around the world. Nevertheless, to our knowledge, this is the first report on the associations of fruit and vegetable intake with CHD risk among Chinese adults with a population-based prospective design and medical record-confirmed cases.

In conclusion, the present results suggest that a higher intake of fruits may be associated with a lower risk of incident CHD in Chinese adults, particularly in women.

\section{Acknowledgements}

The present study was supported by research grants R01HL079123, R37CA070867 and R01CA082729 from the US National Institutes of Health. J. H. was a former trainee of the Vanderbilt-Shanghai Chronic Disease Research Program supported by a grant from the Fogarty International Center (D43TW008313). The US National Institutes of Health had no role in the design, analysis or writing of this article.

The authors' contributions are as follows: X. Z., Y.-T. G., G. Y., W. Z., Y.-B. X. and X.-O. S. designed the research; X. Z., Y.-T. G., H. L., G. Y., W. Z., Y.-B. X. and X.-O. S. contributed to the study implementation and data collection; D. Y. and J. H. conducted the statistical analyses and drafted the manuscript. All authors contributed to the revision of the manuscript, and read and approved the final manuscript. The authors have no conflicts of interest to declare.

\section{References}

1. Dauchet L, Amouyel P \& Dallongeville J (2009) Fruits, vegetables and coronary heart disease. Nat Rev Cardiol 6, 599-608.

2. He FJ, Nowson CA, Lucas M, et al. (2007) Increased consumption of fruit and vegetables is related to a reduced risk of coronary heart disease: meta-analysis of cohort studies. J Hum Hypertens 21, 717-728.

3. Dauchet L, Amouyel P, Hercberg S, et al. (2006) Fruit and vegetable consumption and risk of coronary heart disease: a meta-analysis of cohort studies. J Nutr 136, 2588-2593.

4. Hung HC, Joshipura KJ, Jiang R, et al. (2004) Fruit and vegetable intake and risk of major chronic disease. J Natl Cancer Inst 96, 1577-1584.
5. Oude Griep LM, Verschuren WM, Kromhout D, et al. (2011) Colors of fruit and vegetables and 10-year incidence of CHD. Br J Nutr 106, 1562-1569.

6. Oude Griep LM, Geleijnse JM, Kromhout D, et al. (2010) Raw and processed fruit and vegetable consumption and 10-year coronary heart disease incidence in a population-based cohort study in the Netherlands. PLOS ONE 5, e13609.

7. Tucker KL, Hallfrisch J, Qiao N, et al. (2005) The combination of high fruit and vegetable and low saturated fat intakes is more protective against mortality in aging men than is either alone: the Baltimore Longitudinal Study of Aging. J Nutr 135, 556-561.

8. Joshipura KJ, Hung HC, Li TY, et al. (2009) Intakes of fruits, vegetables and carbohydrate and the risk of CVD. Public Health Nutr 12, 115-121.

9. Boeing H, Bechthold A, Bub A, et al. (2012) Critical review: vegetables and fruit in the prevention of chronic diseases. Eur J Nutr 51, 637-663.

10. Zheng W, Chow WH, Yang G, et al. (2005) The Shanghai Women's Health Study: rationale, study design, and baseline characteristics. Am J Epidemiol 162, 1123-1131.

11. Cai H, Zheng W, Xiang YB, et al. (2007) Dietary patterns and their correlates among middle-aged and elderly Chinese men: a report from the Shanghai Men's Health Study. Br J Nutr 98, 1006-1013.

12. Zhai F \& Yang X (2006) The Nutrition and Health Status of the Chinese People 2002: Diet and Nutrients Intake. Beijing: People's Medical Publishing House.

13. Shu XO, Yang G, Jin F, et al. (2004) Validity and reproducibility of the food frequency questionnaire used in the Shanghai Women's Health Study. Eur J Clin Nutr 58, 17-23.

14. Villegas R, Yang G, Liu D, et al. (2007) Validity and reproducibility of the food-frequency questionnaire used in the Shanghai men's health study. BrJ Nutr 97, 993-1000.

15. World Health Organization (2004) Fruit and Vegetables for Health: Report of a Joint FAO/WHO Workshop, Kobe, Japan.

16. Rose GA \& Blackburn H (1982) Cardiovascular survey methods. In WHO Monograph Series, no. 58. Geneva: World Health Organization.

17. Willett WC, Howe GR \& Kushi LH (1997) Adjustment for total energy intake in epidemiologic studies. Am J Clin Nutr $\mathbf{6 5}$, 1220S-1228S.

18. Matthews CE, Shu XO, Yang G, et al. (2003) Reproducibility and validity of the Shanghai Women's Health Study physical activity questionnaire. Am J Epidemiol 158, 1114-1122.

19. Crowe FL, Roddam AW, Key TJ, et al. (2011) Fruit and vegetable intake and mortality from ischaemic heart disease: results from the European Prospective Investigation into Cancer and Nutrition (EPIC)-Heart study. Eur Heart J 32, $1235-1243$.

20. Desquilbet L \& Mariotti F (2010) Dose-response analyses using restricted cubic spline functions in public health research. Stat Med 29, 1037-1057.

21. Liu S, Manson JE, Lee IM, et al. (2000) Fruit and vegetable intake and risk of cardiovascular disease: the Women's Health Study. Am J Clin Nutr 72, 922-928.

22. Appel LJ, Moore TJ, Obarzanek E, et al. (1997) A clinical trial of the effects of dietary patterns on blood pressure. DASH Collaborative Research Group. $N$ Engl J Med 336, $1117-1124$.

23. John JH, Ziebland S, Yudkin P, et al. (2002) Effects of fruit and vegetable consumption on plasma antioxidant concentrations and blood pressure: a randomised controlled trial. Lancet 359, 1969-1974. 
24. Brown L, Rosner B, Willett W, et al. (1999) Cholesterollowering effects of dietary fiber: a meta-analysis. Am J Clin Nutr 69, 30-42.

25. Thompson GR \& Grundy SM (2005) History and development of plant sterol and stanol esters for cholesterollowering purposes. Am J Cardiol 96, 3D-9D.

26. Hamer M \& Chida Y (2007) Intake of fruit, vegetables, and antioxidants and risk of type 2 diabetes: systematic review and meta-analysis. J Hypertens 25, 2361-2369.

27. Oude Griep LM, Stamler J, Chan Q, et al. (2013) Association of raw fruit and fruit juice consumption with blood pressure: the INTERMAP Study. Am J Clin Nutr 97, 1083-1091.

28. Joshipura KJ, Hu FB, Manson JE, et al. (2001) The effect of fruit and vegetable intake on risk for coronary heart disease. Ann Intern Med 134, 1106-1114.

29. Takachi R, Inoue $\mathrm{M}$, Ishihara J, et al. (2008) Fruit and vegetable intake and risk of total cancer and cardiovascular disease: Japan Public Health Center-Based Prospective Study. Am J Epidemiol 167, 59-70.

30. Nakamura K, Nagata C, Oba S, et al. (2008) Fruit and vegetable intake and mortality from cardiovascular disease are inversely associated in Japanese women but not in men. J Nutr 138, 1129-1134.

31. Liu S, Lee IM, Ajani U, et al. (2001) Intake of vegetables rich in carotenoids and risk of coronary heart disease in men: The Physicians' Health Study. Int J Epidemiol 30, 130-135.

32. Bendinelli B, Masala G, Saieva C, et al. (2011) Fruit, vegetables, and olive oil and risk of coronary heart disease in
Italian women: the EPICOR Study. Am J Clin Nutr 93 , $275-283$.

33. Hirvonen T, Pietinen $P$, Virtanen $M$, et al. (2001) Intake of flavonols and flavones and risk of coronary heart disease in male smokers. Epidemiology 12, 62-67.

34. Rickman Joy C, Barrett Diane M \& Bruhn Christine M (2007) Nutritional comparison of fresh, frozen and canned fruits and vegetables. Part 1. Vitamins $\mathrm{C}$ and $\mathrm{B}$ and phenolic compounds. J Sci Food Agric 87, 930-944.

35. Anderson CA, Appel LJ, Okuda N, et al. (2010) Dietary sources of sodium in China, Japan, the United Kingdom, and the United States, women and men aged 40 to 59 years: the INTERMAP study. I Am Diet Assoc 110, 736-745.

36. Holmberg S, Thelin A \& Stiernstrom EL (2009) Food choices and coronary heart disease: a population based cohort study of rural Swedish men with 12 years of follow-up. Int J Environ Res Public Health 6, 2626-2638.

37. Halton TL, Willett WC, Liu S, et al. (2006) Low-carbohydratediet score and the risk of coronary heart disease in women. $N$ Engl J Med 355, 1991-2002.

38. Blanck HM, Gillespie C, Kimmons JE, et al. (2008) Trends in fruit and vegetable consumption among U.S. men and women, 1994-2005. Prev Chronic Dis 5, A35.

39. Dauchet L, Ferrieres J, Arveiler D, et al. (2004) Frequency of fruit and vegetable consumption and coronary heart disease in France and Northern Ireland: the PRIME study. Br J Nutr 92, 963-972. 